\title{
Clinical Usefulness of Video Head Impulse Test-Comparison of Bithermal Caloric Test and Bedside Head Impulse Test
}

\author{
Hong-Ju Kim ${ }^{1}$, Young-Joo Ko ${ }^{1}$, Hyung-Sun Hong ${ }^{1}$, \\ Seung-Chul Lee ${ }^{2}$, Hyun Ji Kim ${ }^{1}$, and Kyu-Sung Kim ${ }^{1}$ \\ ${ }^{1}$ Department of Otorhinolaryngology-Head and Neck Surgery, Inha University College of Medicine, Incheon; and \\ ${ }^{2}$ Soree Ear Clinic, Seoul, Korea

\section{비디오 두부충동검사의 임상적 유용성; 냉온교대 온도안진검사 및 나안 두부충동검사와의 비교} \\ 김홍주 $^{1} \cdot$ 고영주 $^{1} \cdot$ 홍형선 $^{1} \cdot$ 이승철 $^{2} \cdot$ 김현지 $^{1} \cdot$ 김규성 $^{1}$ \\ 인하대학교 의과대학 이비인후-두경부외과학교실, ${ }^{1}$ 소리이비인후과 ${ }^{2}$
}

\author{
Received July 24, 2017 \\ Revised September 29, 2017 \\ Accepted October 10, 2017 \\ Address for correspondence \\ Kyu-Sung Kim, MD, PhD \\ Department of Otorhinolaryngology- \\ Head and Neck Surgery, \\ Inha University College of Medicine, \\ 27 Inhang-ro, Jung-gu, \\ Incheon 22332, Korea \\ Tel $+82-32-890-3570$ \\ Fax $+82-32-890-3580$ \\ E-mailstedman@inha.ac.kr
}

Background and Objectives Video head impulse test system (vHIT) is an easy-to-use test and there are numerous studies showing its efficacy. The aim of the study was to evaluate the clinical usefulness of vHIT as an initial test in determining vestibular hypofunction in patients with dizziness.

Subjects and Method The study recruited 103 outpatients who visited our ear clinic with dizziness. We performed both bedside head impulse test (bHIT), vHIT and bithermal caloric tests for 103 patients. Both bHIT and vHIT were consecutively performed in each subject on the same day by the same examiner.

Results The sensitivity of bHIT and vHIT was determined based on the bithermal caloric test results, which showed that vHIT was more sensitive than bHIT. There was a significant negative correlation between vHIT gain and canal paresis $(p<0.05)$. Results of some patients indicated dissociation between vHIT and caloric test.

Conclusion There is a significant correlation between the results of vHIT and caloric test. Although vHIT does not replace the caloric test, it would be useful to evaluate the initial vestibular loss in patients with dizziness.

Korean J Otorhinolaryngol-Head Neck Surg 2018;61(8):403-7

Key Words Caloric test - Canal paresis - Corrective saccade - Dizziness ·

Video head impulse test.

\section{서 론}

두부충동검사는 전정안반사(vestibulo-ocular reflex)를 진 료실에서 확인할 수 있는 검사로, 1988년 Halmagyi와 Curthoys" 는 수평반고리관의 일측성 기능저하가 있는 환자들을 대상으로 병측을 향해 빠른 속도로 머리를 회전시킬 경우 보

This is an Open Access article distributed under the terms of the Creative Commons Attribution Non-Commercial License (https://creativecommons.org/licenses/by-nc/4.0) which permits unrestricted non-commercial use, distribution, and reproduction in any medium, provided the original work is properly cited.
상성 단속운동이 발생함을 발견하였으며, 이를 통해 $2 \mathrm{~Hz}$ 이 상 고주파 영역에서의 전정안반사를 평가할 수 있었다. ${ }^{2}$ 두 부충동검사는 안구운동의 측정방법에 따라 공막자기장추적 장치(sclera magnetic search coil system)를 이용한 공막탐 색코일검사와 나안 두부충동검사(bedside head impulse test, bHIT), 비디오 두부충동검사(video head impulse test, vHIT) 로 나눌 수 있다.

공막자기장 추적장치를 이용한 공막탐색코일검사는 두부 충동검사 중 가장 높은 검사 정확도를 보이나 검사 비용이 
비싸고 침습적이라 임상에서 쉽게 사용하기 힘든 단점이 있 으며, 나안 두부충동검사는 진료실에서 쉽게 검사할 수 있으 나 검사결과가 정성적이고 부정확한 단점이 있다.

비디오 두부충동검사는 머리 움직임 동안에 발생하는 안구 의 속도를 측정하는 검사로, covert 홱보기(saccade)를 감별할 수 있을 뿐만 아니라 전정안반사 이득을 직접 측정할 수 있어 나안 두부충동검사에 비해 정확한 정보를 얻을 수 있다. MacDougall 등의 의 연구에 따르면 비디오 두부충동검사는 현재 까지 가장 정밀한 검사인 공막탐색코일검사와 비교하였을 때 에도 전정기능 저하를 진단하는 데 있어 그 진단률에 차이가 없으며, 검사가 비침습적이어서 임상에서 시행하기에 횔씬 간 편한 장점이 있다고 하였다. ${ }^{34)}$ 이러한 이유로 최근 비디오 두 부충동검사 결과의 임상적 의미와 진단 정확도, 질환별 차이 등에 대한 관심이 높아지고 있다.

본 연구는 대부분 병원에서 진료환경상 일차진료 시 온도 안진검사를 우선적으로 시행하기 어렵다는 점을 고려하여 어 지럼으로 내원한 환자의 일차진료 시 비디오두부충동검사를 시행하는 것이, 향후 환자의 전정기능 평가에 임상적으로 도 움이 되는지 확인하기 위해 고안되었다. 이에 따라 어지럼증을 주소로 내원한 환자들을 대상으로 전정기능 저하가 의심되 는 경우 나안두부충동검사, 비디오 두부충동검사 및 온도안 진검사를 시행하였고 말초성 어지럼 환자에서 질환군에 상관 없이 온도안진검사의 반고리관 마비(canal paresis, CP)와 비 디오 두부충동검사 이득(gain) 사이의 상관관계를 확인하여 일차진료 시 비디오 두부충동검사의 임상적 유용성에 대해 확인하고자 하였다. 또한 비디오 두부충동검사와 나안 두부 충동검사를 온도안진검사를 기준으로 각 검사의 민감도, 특 이도를 측정하여, 앞선 연구에서 확인된 바 있는 비디오 두 부충동검사의 진단적 유용성에 대해 확인하였다.

\section{대상 및 방법}

\section{대 상}

본 연구는 2012년 12월에서 2013년 3월까지 어지럼증을 주 소로 본원에 내원한 107 명의 환자 중 검사 시 협조가 되지 않거나, 이전에 중이염수술을 시행받은 자, 내원 당시 심한 어지럼증으로 인해 검사를 거부한 자, 이학적 검사상 중추신 경원인 어지럼증이 예상되어 즉시 신경과로 의뢰한 총 4명의 환자를 제외한 103명(206귀)에서 나안 두부충동검사, 비디 오 두부충동검사, 냉온교대 온도안진검사를 시행하였다. 이 때 나안 두부충동검사와 비디오 두부충동검사는 외래 첫 진 료 시 같은 시험자에 의해 시행되었으며, 온도안진검사는 두 부충동검사 시행 후 3 일 이내에 시행하였다. 본 연구는 인하
대학교병원 임상시험심사위원회(No. 17-010)의 승인을 받은 후 이루어졌다.

\section{방 법}

나안 두부충동검사는 앉은 상태로 정면 눈높이에서 $1 \mathrm{~m}$ 떨 어진 곳의 목표점을 응시한 후 수평면 방향으로 우측과 좌 측 각각의 방향에서 5 번씩 시행하였으며 교정성 홱보기운동 (corrective saccade)이 최소 1회 이상 보일 시 양성으로 판 정하였다.

비디오 두부충동검사는 수평 방향으로 시행하였으며, 회전 진폭은 10 20 , 머리 회전속도(peak head velocity)는 150 $200 \% / \mathrm{sec}$ 로 시행하였다. 비디오 두부충동검사는 국내에서 상 용화된 검사기기인 ICS impulse ${ }^{\circledR}$ (GN Otometrics, Taastrup, Denmark)를 사용하였으며 좌우 각각의 방향마다 무작위로 20 회씩 두부충동을 시행하여 20회 평균 이득 및 overt/covert 교정성 홱보기운동의 유무를 확인하였다. 이때 교정성 홱보 기운동의 유무와 상관없이 이득이 0.8 미만일 때를 양성으로 판정하였다.

온도안진검사는 GN Otometrics 사의 Caloric irrigator (Model NCI-480)를 이용하였으며 냉수는 $30^{\circ} \mathrm{C}$, 온수는 $44^{\circ} \mathrm{C}$ 의 온도로 각각의 귀를 교대로 30 초간 $250 \mathrm{~mL}$ 로 자극하여 안진의 최대 완서상 안구운동 속도를 구하고 Jongnkee의 공 식으로 반고리관 마비가 $25 \%$ 이상의 경우 양성으로 판정하 였다.

통계적 분석방법으로는 chi-square test, independent sample T-test, Pearson correlation을 사용하였고, $p$ 값이 0.05 이 하인 경우 통계적으로 유의하다고 판단하였다. 비디오 두부 충동검사의 진단에 대한 유용성을 평가하기 위해 area under receiver operating characteristic(ROC) 값을 구하였다.

\section{결 과}

본 연구에 참여한 103 명의 대상자 중 남자는 58 명, 여자는 45명이었으며, 나이는 만 15세에서 만 90세까지 분포하였고, 평균연령은 50.5 세였다. 대상 환자의 어지럼증 원인은 일측성 전정장애 34명(33.0\%), 메니에르병 22명(21.4\%), 편두통성 어지 럼 5명(4.9\%), 기타 42명(40.8\%)이었다.

\section{온도안진검사를 기준으로 측정한 나안 두부충동검사와 비디오 두부충동검사의 민감도 및 특이도 비교}

103 명의 대상자, 206 귀 중 58귀에서 반고리관 마비 양성 $(\mathrm{CP}+)$ 을 보였으며 148 귀에서 반고리관 마비 음성(CP-)으로 측정되었다. 반고리관 마비 양성을 보이는 58 귀의 환자 중, 22 
Table 1. Results of caloric test and bHIT in all patients $(p<0.05)$

\begin{tabular}{lcc}
\hline & CP- (\%) & CP+ (\%) \\
\hline bHIT- & $141(95.3)$ & $36(62.1)$ \\
bHIT+ & $7(4.7)$ & $22(37.9)$ \\
\hline
\end{tabular}

bHIT: bedside head impulse test, CP: canal paresis

Table 2. Results of caloric test and VHIT in all patients $(p<0.05)$

\begin{tabular}{lcc}
\hline & CP- $(\%)$ & $C P+(\%)$ \\
\hline VHIT- & $136(91.9)$ & $28(48.3)$ \\
VHIT+ & $12(8.1)$ & $30(51.7)$ \\
\hline
\end{tabular}

VHIT: video head impulse test, CP: canal paresis

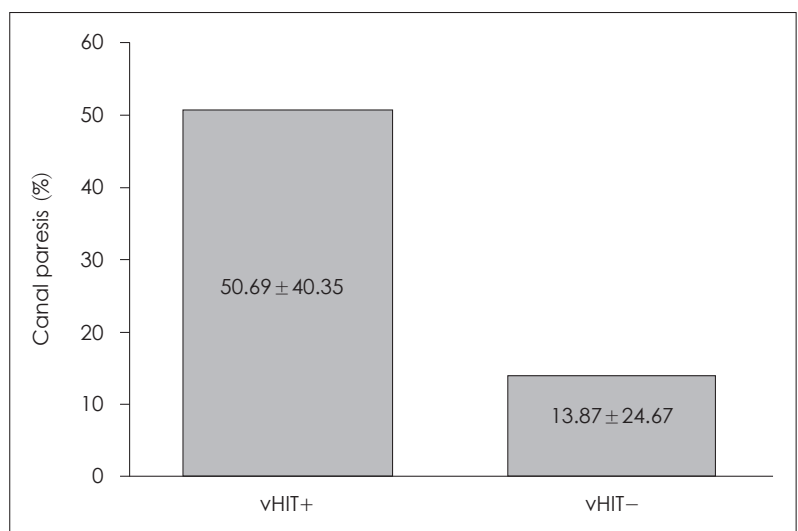

Fig. 1. Canal paresis between VHIT positive group and vHIT negative group. The mean canal paresis of VHIT positive group was significantly higher than that of vHIT negative group $(p<0.05)$. vHIT: video head impulse test.

귀(37.9\%)에서 나안 두부충동검사 양성(bHIT+), 30귀(51.7\%) 에서 비디오 두부충동검사 양성(vHIT+)을 보였으며, 반고리 관 마비 음성을 보이는 148귀의 환자 중 141귀(95.3\%)에서 나안 두부충동검사 음성(bHIT-), 136귀(91.9\%)에서 비디오 두부충동검사 음성(vHIT-)을 보였다(Table 1 and 2).

온도안진검사를 기준으로 보았을 때 비디오 두부충동검사 의 민감도는 $51.7 \%$ 로 $37.9 \%$ 의 나안 두부충동검사보다 높았으 며 특이도는 각각 $91.9 \%, 95.3 \%$ 로 측정되었다(Table 1 and 2).

\section{온도안진검사와 비디오 두부충동검사의 상관관계}

비디오 두부충동검사가 양성일 때 반고리관 마비 평균값 이 $50.69 \pm 40.35 \%$ 였으며, 음성일 때 반고리관 마비 평균값은 $13.87 \pm 24.67 \%$ 로 측정되었다(Fig. 1). 또한 반고리관 마비 양 성일 때 비디오 두부충동검사 이득은 평균 $0.90 \pm 0.30$ 이었 고, 음성일 때 비디오 두부충동검사 이득은 평균 $1.08 \pm 0.17$ 을 보였다(Fig. 2). 이 값들을 Pearson correlation을 통해 분 석한 결과 비디오 두부충동검사의 이득과 반고리관 마비 값 이 유의한 음의 상관관계를 보임을 확인할 수 있었다 $(p<0.05)$

(Fig. 3).

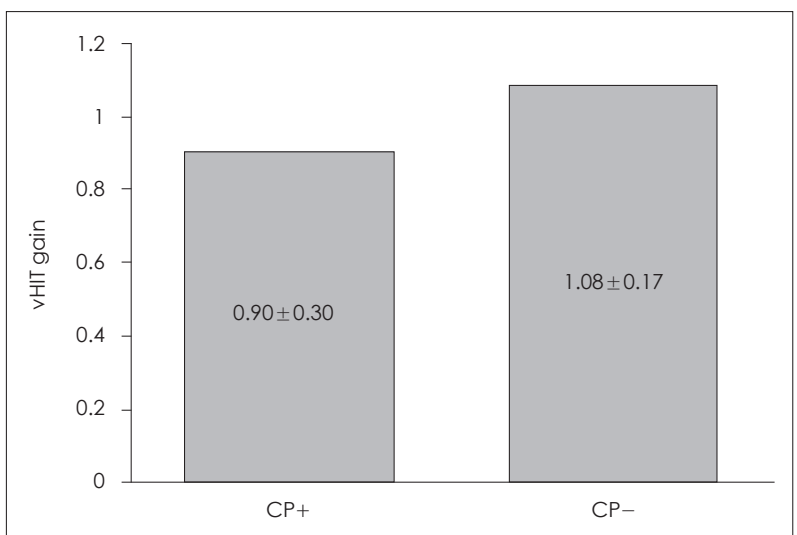

Fig. 2. vHIT gain between canal paresis positive group and canal paresis negative group. The mean VHIT gain of canal paresis positive group was significantly lower than that of canal paresis negative group $(p<0.05)$. vHIT: video head impulse test, CP: canal paresis.

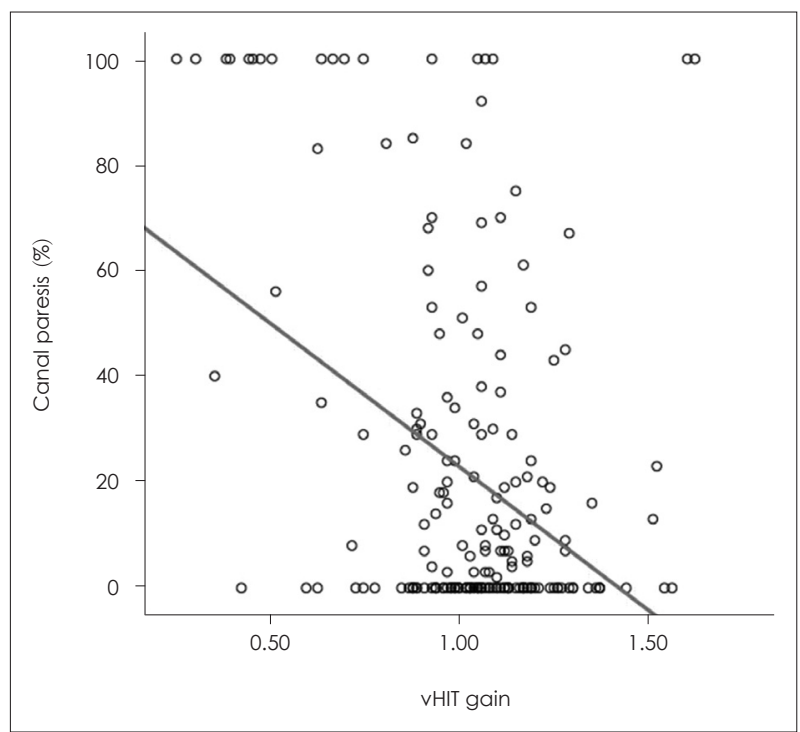

Fig. 3. Pearson correlation plot between vHIT gain and canal paresis. Vestibulo-ocular reflex gain on vHIT shows significant negative correlation with canal paresis on caloric test (correlation coefficient $=-0.387, p<0.05)$. vHIT: video head impulse test.

비디오 두부충동검사의 진단적 유용성을 나타내는 area un-der ROC curve(AUC) 값은 0.7로 측정되었다 $(p<0.05)$ (Fig. 4). Fig. 4의 ROC는 민감도와 특이도가 어떤 관계를 갖 고 변하는지 이차원 평면상에 표현한 것으로 $\mathrm{ROC}$ 곡선 아래 의 면적(AUC)이 넓을수록 좋은 진단방법이라 할 수 있다.

\section{온도안진검사와 비디오 두부충동검사 결과의 불일치}

반고리관 마비 음성을 보이는 148 귀 중 12 귀에서 비디오 두부충동검사 양성을 보였으며, 반고리관 마비 양성을 보이 는 58 귀 중 28 귀에서 비디오 두부충동검사 음성을 보였다. 온도안진검사를 기준으로 비디오 두부충동검사의 위양성률 


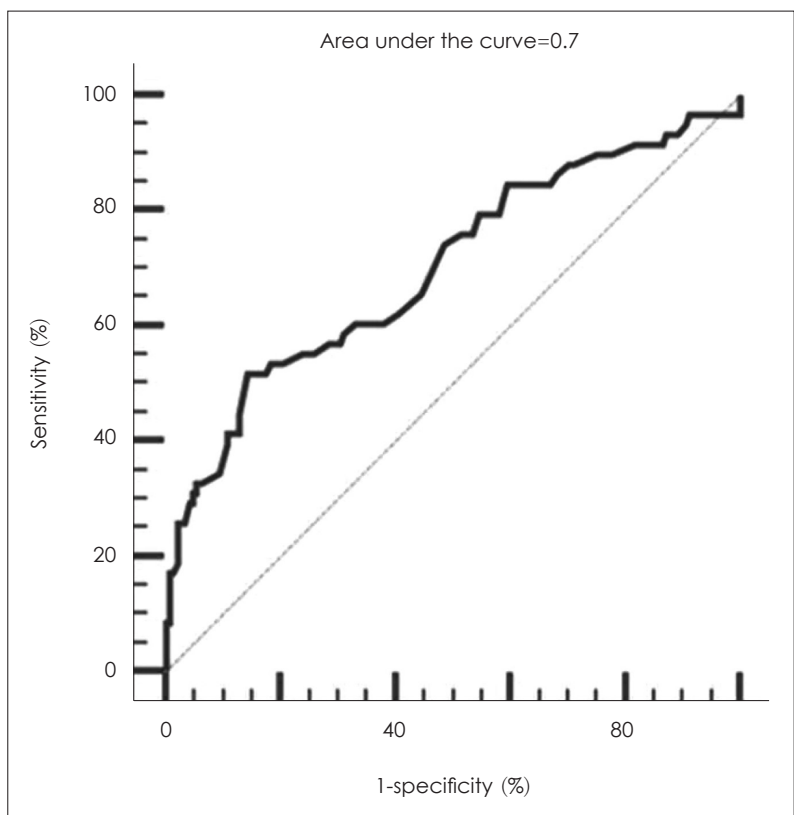

Fig. 4. The plot of area under receiver operating characteristic expresses the model explanation power to be 0.7 .

은 8.1\%였고, 위음성률은 48.3\%였다(Table 2).

\section{고 찰}

두부충동검사는 Halmagyi와 Curthoys가 전정신경절제술 (vestibular neurectomy)을 받은 환자들을 대상으로 시행한 이후 현재까지 전정기능 감소를 확인하기 위한 도구로 자리 잡게 되었다. ${ }^{3,5}$ 두부충동검사의 임상적 유용성에 대해서는 Newman-Toker 등이이 두부충동검사를 포함한 Head-Impulse-Nystagmus-Test-of-Skew(HINTS) 검사가 급성 전정 증후군을 진단하는 데 MRI보다 유용한 것으로 보고한 바 있다.

최근에는 비디오 두부충동검사에 대한 연구가 활발히 진행 되고 있으며, MacDougall 등근 전정기능 저하 환자에서 비 디오 두부충동검사는 그 진단적 가치가 표준 검사인 공막탐 색코일검사와 동등하다고 보고하였고, $\mathrm{Kim}$ 등그는 비디오 두 부충동검사는 홱보기의 성질을 정량적으로 측정하며 모니터 를 통해 적절한 두부 회전속도를 유지할 수 있어 나안 두부충 동검사보다 객관적인 검사결과를 기록할 수 있다고 소개하였 다. 본 연구에서는 비디오 두부충동검사의 민감도 $(51.7 \%)$ 가 나안 두부충동검사의 민감도(37.9\%)에 비해 더 높게 측정되 었으며, 낮은 위음성률을 보였다. 이는 나안 두부충동검사에 서 관찰할 수 없었던 covert 교정성 홱보기운동을 비디오 두 부충동검사를 통해 확인이 가능해졌기 때문이라 생각된다.

비디오 두부충동검사와 다른 전정기능검사를 비교한 이전
연구들에 따르면, 비디오 두부충동검사와 온도안진검사가 각 각 다른 주파수의 전정안반사를 측정하기 때문에 두 검사 사이의 통계학적인 상관관계는 없다는 연구와와 전정기능 장 애 환자에서 비디오 두부충동검사와 온도안진검사를 비교한 결과 약한 일치성을 나타낸다는 보고'가 있었다. 또 다른 연 구에서는 비디오 두부충동검사와 온도안진검사가 높은 일치 성을 보이며 초기 전정기능 저하 평가에 두부충동검사가 유용 함을 기술하고 있다. ${ }^{10)}$ 본 연구에서 비디오충동검사와 온도안 진검사의 상관관계를 비교하였을 때, 비디오충동검사 결과가 양성일 때 반고리관 마비 값이 유의하게 증가된 것이 확인되 었고(Fig. 1), 온도안진검사 양성 환자에서 비디오 두부충동 검사 시행 시 전정안반사 이득이 유의하게 감소한 것을 확인 할 수 있었다(Fig. 2). 또한 비디오 두부충동검사와 온도안진 검사의 Pearson 상관계수의 값( $\mathrm{r})$ 이 -0.387 로 둘 사이의 유의 한 음의 상관관계가 있음을 확인할 수 있었다 $(p<0.05)$ (Fig. 3).

일부 환자에서는 비디오 두부충동검사와 온도안진검사 결 과 사이 불일치를 보였는데, 반고리관 마비 값 양성인 환자 중 43.8\%(58귀 중 28귀)에서 비디오 두부충동검사 위음성이 나 타났다. 이는 비디오 두부충동검사는 고주파 전정안반사를, 온도안진검사는 저주파 전정안반사를 반영한 검사로 질환에 따라 또는 전정기능 저하의 회복 정도에 따라 그 검사결과의 차이를 보일 수 있으며 이는 앞선 연구에서도 확인된 바 있다. ${ }^{11}$ 본 연구에서 위음성을 보인 28 귀 중 12 귀(42.9\%)는 메니에르 병으로 진단되었고 14 귀(50\%)는 전정신경염 환자의 환측 귀 로 확인되었다. 메니에르병은 병의 경과에 따라 비특이적인 전정기능 저하를 보이는데 McGarvie 등은 메니에르병에서 내림프수종의 결과로 온도안진검사의 이상을 유발할 수 있으 나 고주파 전정안반사는 유지되어 두부충동검사는 정상을 보인다고 보고하였다. ${ }^{12)} \mathrm{Kim}$ 등 ${ }^{13)}$ 은 전정신경염의 경우 고주 파 안반사의 회복이 저주파 안반사의 회복보다 빨라 두부충 동검사의 회복 속도가 온도안진검사의 회복 속도보다 빠르다 고 보고하는데, 본 연구에서도 위음성을 보인 전정신경염 환 자의 경우 급성기 이후에 고주파 안반사의 회복으로 비디오 두부충동검사는 정상을 보이나 저주파 안반사의 회복이 느 려 온도안진검사는 양성을 보인 것으로 생각된다.

반고리관 마비 음성인 환자 중 $8.1 \%$ (148귀 중 12귀)에서 비 디오 두부충동검사 위양성을 보였다. 이 중 6 귀 $(50 \%)$ 는 일측 성 전정기능 저하 환자에서 양측 이득이 모두 0.8 이하로 측 정된 경우로, 건 측 6 귀에 대해 위양성으로 분류되었다. 위양 성을 보인 일측성 전정기능 저하 환자 6 명을 분석해 본 결과 병변 측의 이득 평균은 0.58 이었고, 위양성을 보인 건 측의 이 득 평균은 0.78 을 보였으며 이득 비대칭(gain asymmetry)의 평균값을 계산하였을 때 0.14 로 측정되었다. 이때 반고리관 
마비의 방향과 비디오 두부충동검사의 편위 방향은 모두 일치 를 보였다.

비디오 두부충동검사는 나안 두부충동검사보다 민감도가 높고 온도안진검사보다 외래에서 쉽게 시행할 수 있으며 덜 침 습적인 검사로, 본 연구는 어지럼증 환자의 일차진료 시 전정 기능 평가를 위해 비디오 두부충동검사를 시행하는 것의 유 용성을 평가하기 위해 고안되었다. 본 연구결과를 통해 비디 오 두부충동검사가 나안 두부충동검사보다 높은 민감도를 보이는 것을 확인할 수 있었고, 비디오 두부충동검사의 이득 과 온도안진검사의 반고리관 마비 사이에 유의한 음의 상관 관계가 있음을 확인할 수 있었다. 따라서 일차진료 시 온도안 진검사보다 덜 침습적이고 간편한 비디오 두부충동검사를 우선적으로 시행함으로써 환자의 전정기능 저하 여부를 평 가할 수 있다. 다만 앞서 설명하였듯이 질환 및 병의 경과에 따라 위음성을 보이는 경우가 있어 두부충동검사에서 음성 을 보였다 하여 전정기능 저하를 완전히 배제하기는 어려우 며 온도안진검사 등 추가적인 검사를 통해 전정기능에 대한 평가를 요할 것으로 생각된다.

결론적으로 비디오 두부충동검사는 온도안진검사를 대신 하여 어지럼 환자의 초기 평가 시 전정기능 저하를 확인하는 데 유용하며, 어지럼 환자의 초기 평가에서 비디오 두부충동 검사를 통해 양성 시 전정기능 저하를 강력히 의심할 수 있고, 음성 시에는 온도안진검사와 같은 추가 전정기능검사를 통해 전정기능 저하 여부를 평가하는 데 상호 보완적인 역할을 할 수 있다는 점에서 임상적 유용성을 갖는다.

\section{Acknowledgments}

This research was supported by Basic Science Research Program through the National Research Foundation of Korea (NRF) funded by the Ministry of Science, ICT \& Future Planning (NRF-2016R1 C1B2014826).

\section{REFERENCES}

1) Halmagyi GM, Curthoys IS. A clinical sign of canal paresis. Arch Neurol 1988;45(7):737-9.

2) Park H. Vestibulo-ocular reflex for high frequency and acceleration head rotation. Korean J Otolaryngol-Head Neck Surg 2006;49(4): $356-65$.

3) MacDougall HG, Weber KP, McGarvie LA, Halmagyi GM, Curthoys IS. The video head impulse test: diagnostic accuracy in peripheral vestibulopathy. Neurology 2009;73(14):1134-41.

4) Vicky SK, Bachi TH. Head impulse test. Otorhinolaryngology Clinics 2012;4(2):106-11.

5) Weber KP, Aw ST, Todd MJ, McGarvie LA, Curthoys IS, Halmagyi $\mathrm{GM}$. Head impulse test in unilateral vestibular loss: vestibulo-ocular reflex and catch-up saccades. Neurology 2008;70(6):454-63.

6) Newman-Toker DE, Kattah JC, Alvernia JE, Wang DZ. Normal head impulse test differentiates acute cerebellar strokes from vestibular neuritis. Neurology 2008;70(24 Pt 2):2378-85.

7) Kim DY, Choi YG, Kyung TS, Hwang JH, Kim HJ, Lee SC, et al. Cause of false negative bedside head impulse test. Korean J OtolaryngolHead Neck Surg 2017;60(3):107-11.

8) Redondo-Martínez J, Bécares-Martínez C, Orts-Alborch M, GarcíaCallejo FJ, Pérez-Carbonell T, Marco-Algarra J. Relationship between video head impulse test (vHIT) and caloric test in patients with vestibular neuritis. Acta Otorrinolaringol Esp 2016;67(3):156-61.

9) Eza-Nuñez P, Fariñas-Alvarez C, Fernandez NP. Comparison of three diagnostic tests in detecting vestibular deficit in patients with peripheral vestibulopathy. J Laryngol Otol 2016;130(2):145-50.

10) van Esch BF, Nobel-Hoff GE, van Benthem PP, van der Zaag-Loonen HJ, Bruintjes TD. Determining vestibular hypofunction: start with the video-head impulse test. Eur Arch Otorhinolaryngol 2016;273(11): 3733-9.

11) Park P, Park JH, Kim JS, Koo JW. Role of video-head impulse test in lateralization of vestibulopathy: comparative study with caloric test. Auris Nasus Larynx 2017;44(6):648-54.

12) McGarvie LA, Curthoys IS, MacDougall HG, Halmagyi GM. What does the dissociation between the results of video head impulse versus caloric testing reveal about the vestibular dysfunction in Ménière's disease? Acta Otolaryngol 2015;135(9):859-65.

13) Kim JH, Lee TK, Lee SW, Choi N, Lee S, Sung KB. Assessment of vestibular functional recovery using video head impulse test in vestibular neuritis. Res Vestib Sci 2015;14(4):132-8. 